\title{
AN ANALYSIS OF IDENTITY CONSTRUCTION IN INTERACTIONAL NARRATIVES BY WOMEN WITH TURNER SYNDROME ${ }^{1}$
}

\author{
KAMILA CIEPIELA \\ University of Lodz, Łódź, Poland \\ kamila.ciepiela@uni.lodz.pl
}

\begin{abstract}
The study aims to uncover and explore the social identities of women suffering from a genetic disorder called Turner syndrome (TS), and whose main symptoms are a short stature and gonadal dysgenesis. Such a genetically-determined physical appearance is argued to influence the positioning of TS women in the web of social relationships and identities. This linguistic analysis of narratives delivered by Polish women with TS in semi-structured interviews aims to explicate the extent to which they are actors or recipients in creating their own identities. The analysis draws on the assumptions of the 'small story' paradigm developed by Michael Bamberg (1997, 2005) who claims that in interaction, narrative is not only used to convey meaning, but also to construct the identities of the interlocutors. Thus, narrative is treated in a functional way, in which its formal structure and content are integrally associated with its use and any deviations are relativized as a consequence of a user's deliberate activity.
\end{abstract}

Keywords: identity, interview, narrative, positioning, Turner syndrome

\section{Introduction}

The stories that we tell about our own lives, or the lives of other people, are argued to be a pervasive form of text through which we not only make sense of our lives and share our experiences, but also construct and perform identities. Narratologists and discourse analysts (Bamberg 1997; Chafe 1990; Schiffrin 1996) argue that narrative analysis displays how our prior experiences are transformed and symbolized in linguistically-represented events, processes and states. They also posit that "this process of transforming personal experience into verbal performance is interwoven with the way stories are culturally and socially situated" (Schiffrin 1996: 168). Verbalizing our experiences, however, we do not only situate them globally but also locally, selecting particular experiences as relevant to particular interactional settings, audiences and concerns. As Freeman

${ }^{1}$ This work was financially supported by the State Fund for Rehabilitation of Disabled People in Poland. Grant number: BEA/000050/BF/D. 
(2001: 287) notes, "simply put, 'my story' can never be wholly mine, alone, because I define and articulate my existence with and among others", and Schiffrin (2000: 1) observes that in story-worlds, interactions between characters "provide a framework within which relationships - and hence the interacting self and other comprising that relationship - can be situated, displayed, and evaluated".

This article focuses on the process of identity construction that includes a broader sociocultural context, i.e., the ideological orientations of females with Turner syndrome to the issues of femininity, body appearance, and social relations, and the way they position themselves and others in stories they tell about their condition and life in Polish society. The study, referring back to Riessman's idea that narratives are "at core, meaning-making units of discourse" (2002: 705), interprets interactional narratives in terms of the intersubjectivity and reciprocity that operate in the stories, as well as the meanings TS women express with these narratives - that is, an emic perspective is adopted to trace categories, actions, and practices that become meaningful to TS women.

\section{Turner syndrome}

Turner syndrome is a random genetic mutation caused by complete or partial absence of the second sex chromosome. Simply put, affected individuals have one $\mathrm{X}$ chromosome and dysgenesis of the ovaries. They are phenotypically female but lack naturally developing female secondary sexual characteristics. "In genetic terms, these patients are neither male nor female because the second, sexdetermining chromosome is absent. However, phenotypically affected individuals develop as females because there is no Y chromosome to direct the fetal gonads to the male configuration" (Zadrożna 2013: 122). Other major physical characteristics displayed by TS women include short stature, webbed neck, puffiness of the hands and feet, and skeletal abnormalities (Hutaff-Lee, Bennet, Howell, and Tartaglia 2019; Rieser, Davenport 2019; Zadrożna 2013).

A common form of treatment which is also considered to fit TS individuals to a socially accepted female body representation is hormone replacement therapy (HRT); the procedure is typically carried out on them early in their life, and thus conscious consent for the therapy is given by their parents rather than the girls. From the medical perspective, HRT is considered beneficial for an individual because it either eliminates or amends bodily abnormalities, and prevents osteoporosis. As a result, the psychological wellbeing and self-esteem of an individual are claimed to improve (Hutaff-Lee, Bennet, Howell, and Tartaglia 2019; Toft, Rehan 2014; Zadrożna 2013).

Not all women with TS, however, can benefit from growth hormone (GH) therapy, either because of its unavailability or high cost. In Poland, the Ministry of Health began to reimburse growth hormone therapy for girls with Turner Syndrome in 2000 (Świątkiewicz-Mośny 2010), which means that the girls whose puberty terminated before that year never received GH therapy since it has been 
proved ineffective after puberty. As a result, the body height of these women is, on average, 20 centimeters shorter than the mean for the population, and does not exceed 140 centimeters.

The overall stigma associated with having Turner Syndrome, the short stature and other body abnormalities may "exacerbate the degree to which women feel that their bodies do not conform to the unrealistic standards prescribed by their culture, and consequently might have a greater impact on women's self-esteem and body image concerns" (Cragg \& Lafrenier 2010: 437). Rieser and Davenport (2019: 2) argue however, that "[m]ost girls with TS are healthy and well-adjusted even though some face special physical, emotional, social or learning challenges." This leads us to the conclusion that generalizations about the socio-emotional functioning of TS women may be highly speculative, which only highlights the value of narrative analysis that focuses on idiosyncrasies and peculiarities of individual experience.

The article, therefore, examines the abilities of narratives to verbalize the experiences of adult TS women with their body condition and HRT in mundane life situations, with which globally and locally relevant identities can be constructed and performed.

\section{Narrative analysis}

Narrative analysis is argued to provide "a systematic way of understanding how people make events in their lives meaningful, as well as how they engage in the ongoing construction of their identities" (Bell 2006: 235). One of the most recent frameworks for situational identity construction was proposed by Michael Bamberg in his seminal article Positioning between Structure and Performance (1997), where he argues that the process of positioning happens at three different levels: (i) story, (ii) interaction, (iii) socio-cultural discourse. An analysis based on the first level positioning shows how characters are construed within the story events, for example as agents, targets, protagonists or antagonists. At the second level, the analysis takes into consideration the purpose of the narrative, its setting and its co-construction by both the narrator and their audience (Schnurr, Van De Mieroop \& Zayts, 2014) whereas the third level analysis deals with how narrators construct themselves as particular kinds of people (Bamberg and Georgakopoulou 2008: 391), and this extends beyond the level of the storytelling situation to larger socio-cultural discourses. The third level is claimed to connect the first two levels "which are related to the narrated events in the here and now of the storytelling situation to speakers' ways of making sense of their identities within wider terms of understanding as provided by global macro discourses" (Al-Bundawi 2019: 44).

In this article, the analysis is conducted on the third level, which is described as a 'middle ground' because it "allows for linking local talk and identities with socio cultural processes and relations that surround and have an impact on the local interaction in more or less direct ways" (De Fina 2013: 58). An analysis of 
a story at the third level displays "how narrators and audiences negotiate less locally produced senses of who they are, i.e. their membership into social identities, moral identities, etc." (p. 43), and the links between the local level of interaction and the global can be made by taking into consideration patterns that occur in the data, which might "point to collective positioning processes" (De Fina 2013: 46).

\section{Analysis of stories}

\subsection{Method}

This is qualitative research that focuses on interactional behaviors of TS individuals in open-ended interviews. It follows an inductive path that begins with a few perceived notions such as short stature, gonadal dysgenesis or hormone substitution therapy, and continues with a gradual fine-tuning and narrowing of focus on TS female identity construction in conversational narratives.

\subsection{Data}

The data for the analysis in this article are made up of sample narratives of a larger corpus that encompasses ten semi-structured interviews with Polish women with TS.

The interviews were semi-structured in the sense that they started with a request directed at the interviewees to define Turner syndrome, and closed with two evaluative questions about the impact of TS on the real and possible (future) self that the interviewees could perceive. The aim of the opening question was to embed the talk in the discourse of Turner syndrome, while the closing questions targeted the core subject of the research, namely identity construction by TS individuals.

In terms of narrative structure, the organization of the interview is reminiscent of Russian dolls, i.e., the opening request constitutes a frame and other "stories contained in it are recurring elements that may nest inside each other" (Fludernik 2009: 29). Lower level narratives told by each participant of the interview may also become frame narratives that are found next to each other, without any explicit reference to verticality. An example of such horizontal framing may be an account of growth hormone therapy, school harassment or employment discrimination. The closing questions generate the narrowest frame narrative that portrays the teller herself against the backdrop of Turner syndrome characteristics.

The aim of the interviews was to gain some insight into the ways that the cultural experiences of TS women in the home and community compare with the culture of the schools, universities, workplaces, and communities where they live, study, and work, and to trace possible implications of these differences for the identity construction of these women in private and public discourses. 
The narratives that are analyzed in this article come from interviews with two TS women. They were conducted in Polish, audio-recorded, transcribed and translated to English with a simplified transcription convention, as in Jefferson (2004). The interviews for the analysis in this article were otherwise randomly selected but for one criterion, namely whether growth hormone (GH) therapy was received by the interviewee.

\subsection{Participants}

A total of 10 adult women with TS participated in the study. Of these, the stories of two women, whose pseudonyms are Eva and Lena, are analyzed in this article. Eva is 53, lives in a medium-sized town in western Poland, is employed on a temporary contract as a cleaner, and has recently been involved in a heterosexual relationship. Lena is 27 , lives in a medium-sized town in eastern Poland, works for a publishing house, and recently became engaged to be married. Both women graduated from universities.

\subsection{Analysis}

The analysis of the narratives from the interview aims to present the extent to which TS is constitutive and agentive in the identity construction of women with TS. In particular, the focus of the analysis falls on the relationship between selfimage and social stigmatization of women who received growth hormone $(\mathrm{GH})$ and those who did not. It is hypothesized that women who did receive GH and are average in stature, would have a more positive body image than women who did not receive it. They would also be less stigmatized, if at all, because GH therapy allowed them to reach an average height, and hence erased the most ostensive "mark" of TS. Finally, because of the absence of any visible imprint of TS on women who received $\mathrm{GH}$, and thus little stigmatization based on bodily appearance, they would be argued to be more agentive and empowered in the acts of identity marking, as well as in the construction of social relationships with "the other".

\subsubsection{Eva}

Eva is 53, and her height is $140 \mathrm{~cm}$. She was diagnosed with TS in late childhood but she never received growth hormone because her father did not give his consent for the treatment. She experienced physical abuse from her father, and her mother never defied him to support her daughter. At the time of the interview, Eva lives an independent life working as a cleaner, which is far below her qualifications, as she is a university graduate. The work is badly paid and very exhausting for her. Her main concern is to receive a certificate of moderate disability that would qualify her for a disability pension; yet her application has already been rejected once, and she is now going to make another attempt to obtain it. 
Eva: I basically had no idea about this disease, what it was, because there were no talks or anything with my parents. I thought it was just about growth. one day I told my mother that I felt bad about those pills. don't take them ((imitates mom's voice)), she said.

Interviewer: $\mathrm{mhm}$

Eva: I stopped taking them, I thought they were futile. later, years later, it turned out that I had a referral for treatment abroad, in Sweden or somewhere, but of course they didn't even tell me about it

Interviewer: your parents? cause you were underage?

Eva: yes parents. well, my father forbade them from treating me and that's how it came out, neither treatment nor disability pension. a few girls I know have a pension and have a moderate disability certificate, so they have a disability pension and nursing allowance and now the thirteenth pension comes, you know

Interviewer: yeah

Eva: and I am struggling now cause I have nothing, neither a disability certificate, nor a pension nor anything because I didn't know about it at all

$((\ldots))$

Eva: yeah, yeah, as I say, I did not know life, I could not talk, at home they also did not talk normally, only insults and this (...), my mother didn't, only my father called names, I will not repeat, I did not know what was important in life, how to speak, how to talk, I wasn't taught that, only life has taught me

The key activity that spans the narrative in Excerpt 1 is verbal communication, and the core event is grounded in the situation in which Eva informs her mother that she feels bad after taking the pills that were to treat the disease mentioned in the first line of this excerpt. Eva's mother responds to her daughter's doubts producing a short imperative sentence: "Don't take them" that sounds dry and disengaged. This attitude of Eva's mother receives very strong prominence since Eva produces it by imitating her mother's snippy, condescending tone. Back in the story, Eva obeys her mother's command and ceases the therapy inferring that the therapy is pointless. To prove that her interpretation of her mother's attitude is correct, Eva jumps forward over several years to the day that she finds that her parents, her father in particular, deliberately deprived her of a more advanced and probably effective therapy that could change the course of her life by withholding relevant information from her ("my father forbade them from treating me and that's how it came out, neither treatment nor disability pension"; "I have nothing, neither a disability certificate, nor a pension nor anything because I didn't know about it at all").

This earlier lack of knowledge about her condition and possibilities of treatment is argued to be consequential for Eva's present life since she does not qualify for a disability pension. This argument seems illogical since medical treatment and therapy aim at bringing an individual to such a physical condition that would enable them to do their job, rather than live on a pension. This apparent contradiction in Eva's argumentation is resolved in the evaluation of the narrative 
when she states that the major problem stemming from her family life and upbringing was underdeveloped communicative skills (I didn't know how to speak, how to talk, I wasn't taught that). She admits that she has been struggling to change the situation and learn how to interact with others (agentive selfpositioning), yet the achievement is insufficient (I have nothing) to satisfy Eva's needs, and worse she admits that she failed and has been positioned by the dominant discourse of disability (life has taught me).

The evaluative statements made by Eva provide concrete support for scholarly presumptions that the development of knowledge expected of members of a particular community is made possible by the symbolic resources provided through language and non-verbal communicative acts as they are realized in communication (Mead 1934). In other words, as Schiffrin (2006: 106) notes, "we learn standards of acceptable behavior by observing how others respond to us, anticipating others' responses, developing responses that are designed for others, and integrating them into our own repertoire of actions and meanings". Eva's interactions with her mother or father did not provide her with adequate symbolic resources that could be transported and utilized in a larger range of social contexts, and thus permit successful communication and the accomplishment of interactional goals. Now that many years have passed, she is still struggling to put her message across when, for instance, settling official matters like getting a disability certificate.

The family communicative events seem to have been deficient in two basic assumptions that pervade every interaction, namely intersubjectivity and reciprocity. The former emphasizes the awareness of being "involved in the same process" (Mead 1934: 154) which is "based on either similarities (everyone can do the same work) or complementary differences (people can do different tasks that combine to produce a single product)" (Schiffrin 2006:107), while the latter can be understood as gifts that interactants exchange for what they have been offered and what they will be given in the upcoming action (Mauss 1967). Seemingly, in the recounted conversation with her mother, Eva is an active interactant who does the same work as her mother; she takes turns speaking, receiving and acting in the interaction. Admittedly, she initiates the exchange about the pills and her health with her mother, yet, the goal she sets for herself, to discuss the problem with her mother, is not accomplished. Rather than advice, she gets an order realized with the imperative "Don't take them" that resists any negotiation, and thus brings the interaction to a close. This illustrates the interactional asymmetry of the I-you relationship, in the sense that Eva's actions are implicated in her mother's actions but the reverse does not hold. The issue that Eva intends to focus on is her feelings about the treatment, while her mother selects "pills" and makes it the basis of her response. With this move, the mother self-positions as capable of directing the course of interaction, while Eva becomes a recipient of the message deprived of an opportunity to manage the direction of the interaction or to accomplish her interactional goals.

The other foundational assumption of interaction, as Schiffrin (2006) argues, is reciprocity based on complementary differences between interactants and 
actions that they perform. Mauss (1967) construes reciprocity as gifts that interactants exchange as a result of prior actions or anticipated upcoming actions. Reciprocity implies that the actions of one interactant complement those of the other. In the recounted conversation, Eva received a requisite response from her mother but she did not offer her any "gift" in return, even if her mother designed her talk so as to suppress it. Later in Excerpt 1, Eva talks about the various documents she wanted to obtain; by analogy, the documents can be viewed as some kind of a gift she demands from public institutions that represent "the other" in that context. As in the local context of the interaction with her mother, Eva fails in accomplishing her goals in other social contexts where "the other", represented by an institution or organization, is less distinct and thus more difficult to communicate with.

The analysis of intersubjectivity and reciprocity operating in the narrative events recounted by Eva helps provide a view of how "I" and "you" are brought together as internalizations of society. Depicting events through narrative in which her own self is involved, and placing this self in relation to others, Eva makes a choice of positioning. She picks low-agency marking devices (semantic role of patient; syntactic function of object) that construe "the direction of fit from worldto-person" and "assist in the construction of a victim role or at least a position as less influential, powerful, responsible" (Bamberg et al. 2011: 187). In contrast, presenting her parents, she picks devices that lean toward "a person-to-world direction of fit" (semantic role of agent, syntactic function of subject), and positions them as agentive, strong, and in control of the ongoing interaction as well as her condition and treatment. Similarly, "life", which can be understood as the generalized other, receives the agentive power to steer the course of events that Eva lives.

\subsubsection{Lena}

Lena is 27 , and her height is $160 \mathrm{~cm}$. She was diagnosed with TS when she was six. Soon after, she started GH therapy that lasted for six years. Before she was diagnosed with TS, she had been diagnosed with celiac disease that, in Lena's opinion, caused many more psycho-somatic problems than TS. In her struggle with her health condition, she received great support from her parents. At the time of the interview, Lena is a university graduate with degrees in three different majors, each related to the Humanities. She lives with her fiancé and works in a publishing house as a marketing specialist. That job is not well-paid, and is rather tedious to her. She is trying to find another one, which is not easy, because the unemployment rate in the region of Poland where she lives is fairly high. Her main concerns at the time of the interview are to find a more challenging job and to get ready for the wedding that is a year ahead.

\section{Excerpt 2}

Interviewer: do you remember yourself at the time of the diagnosis?

((a number of lines skipped)) 
Lena: the only thing that was harder for me in my social life was the time I had to take the growth hormone, because I was told that at 08:00 pm I should take it. I reacted in such a way that at 08:30 I was asleep. it made me so drowsy, like some melatonin. nightmare! so I just knew. I didn't even ask my parents if I could, I knew I couldn't go to a friend's for a night or go on a school trip. I always said nope because I knew my class was stupid. here you have to name things by their names, they would never understand what it means to have a needle, medicine, and besides, such purely technical things as to have an icebox on me. it's so awkward for teens. I always had the impression that I was a few steps ahead of my peers. this has remained, maybe because of selfdiscipline, because I put on weight easily, I had to have discipline at home, I had to do exercises, ride my bike for twenty kilometers a day, I truly thank my father for that today, because only now that I took care of myself and lost eighteen kilograms and ten more needs to be lost before the wedding, but if I wasn't rebellious and listened to my dad, I wouldn't have to do it now. I have a task-oriented character, take the medicine - I take the medicine, change the patch, because I am on hormone replacement therapy in patches, and I change it. In summer I remember I had to count and change the place where to stick it here or there. well, you know, like a young girl in summer. Then one day I knocked on my head and told myself, oh God, you are stupid, Lena. You're ashamed that you're carrying that burden and you're doing great! I raised my spirits and then I didn't give a fuck, I didn't care if they were really laughing at me or not.

Interviewer: were you stigmatized at school by peers?

Lena: I told no one because the celiac isolated me and I knew nobody would understand turner's

((some lines skipped))

Lena: you are an intelligent woman familiar with an ampoule, pen, all this needs to be calculated, so how could I go on a trip and risk that they would make it into a toy. was I supposed to walk with this icebox everywhere?

Excerpt 2 contains a fairly long narrative that evolves in a response to the interviewer's question about Lena's memories of the time of the TS diagnosis. The story that frames the social relationships that Lena established at that time nests two parallel stories that each contain one of a socially-distinct-group participant, i.e. parents or peers, and Lena who recurs as a protagonist in both. The characters in each story are designed differently. Lena's peers are depicted as irresponsible, childish and incapable of understanding the seriousness of GH therapy (stupid; they would make it into a toy). Lena, in contrast, is shown as much more mature, responsible and knowledgeable about her own condition as well as the level of cognitive and social development of her peers (I knew nobody would understand turner's; I was a few steps ahead of my peers). In the other story, the bulk of positive attributes move to the parents who are not only fully aware of Lena's condition but are also knowledgeable about the possibilities of treatment and the regime of GH therapy (they set the time of GH injection, amount 
of exercising or cycling distance to be covered daily). Lena is closely supervised as well as taken care of by her parents, which, despite triggering acts of revolt in her (if I wasn't rebellious), is also considered the only way to improve her condition, which she seems to have internalized (I didn't even ask my parents, I knew I couldn't go). In other parts of the interview, Lena recounted many occasions when her parents talked with her about her health issues and discussed possibilities of treatment and therapy. These talks fostered her ability to adopt multiple perspectives on the issue of health simultaneously, and allowed not only for a more complex understanding of TS and celiac disease, but also, as Tomasello (2001) argues, for the internalization of the view of the other as oneself, and the socially mediated forms of self-experience (I raised my spirits and then I couldn't give a toss, I didn't care if they really laughed at me or not; You are ashamed that you're carrying that burden and that you're doing great) that eventually led to the ability to critically self-monitor Lena's own behavior and cognition (earlier celiac isolated me and I knew nobody would understand turner's; all this needs to be calculated, so how could I go on a trip and risk that they would make a toy of it; I took care of myself and lost eighteen kilograms and ten more is ahead to lose).

The two stories also expound different perspectives of intersubjectivity and reciprocity. Lena and her peers, as story characters, are involved in one and the same process of communication based on mechanical solidarity (Durkheim 1966 [1895] cited in Schiffrin 2006: 107) in which they engage in similar tasks (simultaneity of "I" and "you", and exchange of self and other) to produce the final product, namely, to bridge the information gap. The differences between the characters, however, are not complementary but antagonistic (Lena has to return home before 8:00pm, the peers don't; Lena has TS, the peers do not; Lena knows the importance of medical treatment, diet and exercise and the peers do not), and therefore they cannot produce a single product, i.e. mutual understanding. Lena is not willing to disclose her condition, and communicates with her peers in short utterances displaying agreement or disagreement that do not leave space for negotiating meaning or making inferences. Furthermore, messages conveyed in short utterances are easier to coordinate with non-verbal signals, i.e., what is intended and produced on a linguistic level will not be contradicted on an expressive level, which enables Lena to manage the interaction efficiently. It is her who has an opportunity to select the facet of the utterance produced by the peers that will be the basis of her response, while the possibilities of making such choices by the peers are heavily reduced. There is little reciprocity founded on organic solidarity (Durkheim 1966 [1895] cited in Schiffrin 2006: 107), and communicative actions that would facilitate the trade-off of self and the other are also reduced (Lena does not disclose her condition or explain what TS is; the peers are not inquisitive). Such interaction with little reciprocity serves only one basic function, namely, to communicate, at intuitive and automatic levels, with members of the same species (Cortina and Liotti 2010). It also allows Lena to take total control over the production of her public self while simultaneously saving the private one. 
The story about Lena's parents reveals a different internalization of the selfother relationship. Here the characters share a majority of the symbolic resources that they use to communicate and collaborate in constructing their social roles. First of all, they share the knowledge about Lena's condition and possibilities of treatment and therapy. This can be inferred from Lena's utterance "I didn't even ask my parents if I could, I knew I couldn't go to a friend's for a night or go on a school trip", which implies that her parents had the knowledge that they put to use directing and controlling Lena's behavior and therapy. That Lena also had relevant knowledge is overtly acknowledged in the utterance "I knew I couldn't go". Having similar knowledge further suggests that the characters can do the same work in the interaction, that is embrace or retreat from a situated role and manage the roles of others. Thus, intersubjectivity based on mechanical solidarity holds in the interactional encounters between Lena and her parents. The simultaneity of "I" and "you" is also evident in the semantic structure of the sentences Lena uses to tell her story; in "I didn't even ask my parents", Lena is 'agent' and her parents represent 'source', and in "I thank my father for that" Lena is 'agent' again and father is 'beneficiary'. The former also implies that Lena would get an answer from her parents whenever she asked, and the fact that she knew the answer implies that such situations recurred. The latter implies collaboration between two parties that possess complementary powers and capabilities. Thanksgiving is usually performed on the occasion of receiving something as a result of prior actions. In the interview, Lena admits that she is thankful to her father for the regime he introduced for her when he learned about her condition, yet this act of thanksgiving is performed many years after she had received the care and advice. Immediately after receiving them, Lena was not satisfied with the gift. She says she was rebellious. This may suggest that reciprocity was absent from earlier encounters between the parents and their daughter. Rather it developed in and through continuous parent-daughter interactions that provided Lena with the understanding that her actions are implicated by her parents' actions and vice versa.

The analysis of intersubjectivity and reciprocity operating in the narrative recounted by Lena shows how self and other are constructed in different social contexts and how agency is inscribed in these roles. In each story, Lena is constrained by societal forces like peers or parents, as well as dominant discourses of institution (school, family) and medicalization. In each story, however, she retains an agency that enables her to either comply with or resist these forces and the identities inscribed in them. When her schoolmates invite her to a party or a school trip, she credits herself with an agency to reject their offer and select an option that she has internalized as optimal. That choice, however, is controlled by her health condition, and indirectly by parents who are decisive about the therapy. So, despite being agentively involved in the interactions with her peers, Lena is constrained by the dominant discourses of Turner syndrome therapy and family ("I didn't even ask my parents because I knew I couldn't go"). Furthermore, Lena's agentive positioning in interactions with her peers is marked with her overtly categorizing them as "stupid" and herself as "a few steps ahead of them", 
and with labeling actions that they would perform vis-à-vis her own actions ("they would never understand"; "I didn't even ask my parents if I could, I knew I couldn't").

That Lena's choices were not absolutely free, and that she was ridiculed and stigmatized, is implied in another "small story" (Bamberg \& Georgakopoulou 2008) that she delivers to lodge a claim about her present-day position. She acknowledges that it took her years before she arrived at a favorable self-image ("you are stupid, Lena. you're ashamed that you are carrying that burden and that you're doing great!"). That moment of reflection on her life experiences and condition is used by Lena to build her position vis-à-vis her former self. She looks back at what has happened earlier through the lens of her subsequent experiences and places herself in the position of rejection of the dominant discourses of Turner syndrome as a disease or disability that has a hold over her life. It was true of her former position, when the TS therapy had an absolute control over her physical and social life. The expression "it made me so drowsy" places Lena at the recipient end of the agency-recipiency continuum (Bamberg 2011), which is further strengthened when the effect of GH therapy is metonymically conceived of as the effect of melatonin - both having total power over the psycho-somatic functions of a human being. That Lena no longer accepts such positioning is indicated by the evaluative "nightmare" produced at the end of the initial episode of the story. Then at the turning point she "knocked herself on her head" and self-positioned at the other end of the agency-recipiency continuum (Bamberg 2011). Her agency is visible in her resisting the actions of her peers ("I didn't give a fuck, I didn't care if they really laughed at me or not"), and in complying with the actions of her parents ("I truly thank my father for that today").

The evolution of Lena's position from "world-to-person" to "person-toworld" (Bamberg 2011) is also evident in lexico-syntactic devices she uses to talk about her former and present self. Presenting her former self, she predominantly picks low-agency marking devices (passive voice, syntactic function of object, static verbs, verbs expressing subordination - tell, make), whereas presenting her present self, she picks narrative devices that lean toward high-agency (active forms of action verbs, subject position).

\section{Conclusion}

The article aims to present the abilities of narratives to verbalize the experiences of adult TS women with their body condition and the extent to which TS is constitutive and agentive in the identity construction of these women. It was hypothesized that women who received $\mathrm{GH}$, and are average in stature, would be more agentive and empowered in the acts of identity marking as well as in the construction of social relationships with "the other".

The analysis has shown that in constructing their identity, women with TS are entangled in a complex web of social interdependencies that make them feel either a victim on some occasions or someone in control of others. Focusing on Eva's 
case, we can see that a TS woman who has been deprived of GH therapy selfpositions at the receiving end of the "world-to-person" continuum and thus marks herself as being swept into the TS condition, and that this positioning does not evolve over time. The other case, a woman who was provided with $\mathrm{GH}$, embodies a diachronically and synchronically varied process of identity construction. The agency dilemma is resolved contrastively in contexts that involve different interlocutors. In private and intimate situations where interlocutors are informed of her condition, Lena is less agentive than in contexts that involve strangers uninformed of her condition. Nonetheless, these positionings change diachronically. When the TS mark has disappeared as a result of GH therapy, Lena firmly places herself at the agentive end of person-to-world continuum - thereby constructing a sense of continuity and development across her lifespan.

Interactional narratives have been shown to be the empirical domain and device in which identities emerge and develop, and can be dissected and examined. On the one hand, storytellers use interactional narratives to "manage and fine-tune their resources in order to come across in alignment with institutional and interpersonal demands" (Bamberg 2005: 221). On the other hand, paying attention to the form and contents of a story, the analyst can see how these stories are used to work up identity claims that frequently appear as complex or even conflicting, and not too obvious at the level of linguistic performance.

\section{References}

Al-Bundawi, Zayneb. 2019. Place-attachment as a master narrative in the interviews of Shi'i Muslim Women in the diaspora. In Kamila Ciepiela (ed.), Language, identity, community, 41-52. Frankfurt-am-Main: Peter Lang.

Bamberg, Michael. 2005. Narrative discourse and identities. In Jan, Christoph Meister, Tom Kindt, Wilhelm Schernus. (eds.), Narratology beyond literary criticism. mediality, disciplinarity, 213237. Berlin, New York: Walter de Gruyter. https://doi.org/10.1515/9783110201840.213

Bamberg, Michael. 1997. Positioning between Structure and Performance. Journal of Narrative and Life History, 7 (1-4), 335-342. https://doi.org/10.1075/jnlh.7.42pos

Bamberg, Michael, Anna De Fina, and Deborah Schiffrin. 2011. Discursive perspectives on identity construction. In Seth Schwartz, Koen Luyckx, and Vivian Vignoles (eds.), Handbook of identity theory and research, vol.1, 177-199. Berlin/New York: Springer Verlag. https://doi.org/10.1007/978-1-4419-7988-9_8

Bamberg, Michael, and Alexandra Georgakopoulou. 2008. Small stories as a new perspective in narrative and identity analysis. Text and Talk, 28(3), 377-396. https://doi.org/10.1515/TEXT.2008.018

Bell, Susan, E. 2006. Becoming mother after DES: intensive mothering in spite of it all. In Anna de Fina, Deborah Schiffrin, and Michel Bamberg. (eds.) Discourse and identity, 233-252. Cambridge: Cambridge University Press. https://doi.org/10.1017/CBO9780511584459.012

Chafe, Wallace. 1990. Some things that narrative tells us about the mind. In Bruce, K. Britton, and Anthony, D. Pellegrini. (eds.) Narrative thought and narrative language, 79-98. Hillsdale, NY: Erlbaum.

Cortina, Mauricio, and Giovanni Liotti. 2010. Attachment is about safety and protection, intersubjectivity is about sharing and social understanding: The relationships between attachment and intersubjectivity. Psychoanalytic Psychology, 27(4), 410-441. https://doi.org/10.1037/a0019510 
Cragg, Stephanie. J., and Kathryn, D. Lafreniere 2010. Effects of Turner Syndrome on Women's Self-Esteem and Body Image. Journal of Developmental and Physical Disabilities, 22:433-445. https://doi.org/10.1007/s10882-009-9178-0

De Fina, Anna. 2013. Positioning level 3: Connecting local identity displays to macro social processes. Narrative Inquiry, 23(1), 40-61. https://doi.org/10.1075/ni.23.1.03de

Durkheim, Emile. 1966 [1895]. The rules of sociological method. New York: Free Press.

Fludernik, Monika. 2009. An introduction to narratology. (transl. Patricia Häusler-Greenfield \& Monika Fludernik). New York: Routledge. https://doi.org/10.4324/9780203882887

Freeman, Mark. 2001. From substance to story: narrative, identity and the reconstruction of the self. In J. Brockmeier and D. Carbaugh (eds.), Narrative and identity: studies in autobiography, self and culture, 283-298. Amsterdam and Philadelphia: John Benjamins. https://doi.org/10.1075/sin.1.16fre

Hutaff-Lee Christa, Elizabeth Bennett, Susan Howell, and Nicole Tartaglia. 2019. Clinical developmental, neuropsychological, and social-emotional features of Turner syndrome, American Journal of Medical Genetics, 181C: 42-50. Available from: https://doi.org/10.1002/ajmg.c.31687 [Accessed: 25th January 2020].

Jefferson, Gail 2004. Glossary of transcript symbols with an introduction. In G. H. Lerner (ed.), Conversation Analysis: studies from the first generation, 13-31. Amsterdam: John Benjamins. https://doi.org/10.1075/pbns.125.02jef

Mauss, Marcel. 1967. The gift. New York: Norton.

Mead, George 1934. Mind, self, society. Chicago: University of Chicago Press.

Rieser, Patricia, and Marsha Davenport. 2019. Turner Syndrome: a guide for families. Available from: http://www.turnersyndrome.org/dmdocuments/TSfamily guide092502B.pdf [Accessed: 25th January 2020].

Riessman, Catherine, Kohler. 2002. Analysis of personal narratives. In Jaber, F. Gubrium and James, A. Holstein (eds.) Handbook of interview research, 695-710. Thousand Oaks: Sage. https://doi.org/10.4135/9781412973588.n40

Schiffrin, Deborah 1996. Narrative as self-portrait: Sociolinguistic constructions of identity. Language in Society, 25, 167-203. https://doi.org/10.1017/S0047404500020601

Schiffrin, Deborah. 2000. Mother/daughter discourse in Holocaust oral history. Narrative Inquiry, 10(1), 1-44. https://doi.org/10.1075/ni.10.1.01sch

Schiffrin, Deborah. 2006. From linguistic reference to social reality. In Anna de Fina, Deborah Schiffrin, \& Michael Bamberg (eds.), Discourse and identity, 103-131. Cambridge: Cambridge University Press. https://doi.org/10.1017/CBO9780511584459.006

Schnurr, Stephanie., Dorien Van De Mieroop, and Olga Zayts. 2014. Positioning oneself in relation to larger collectivities in expatriates' workplace narratives. Narrative Inquiry 24(2), 386-407. https://doi.org/10.1075/ni.24.2.11sch

Świątkiewicz-Mośny, Maria. 2010. Tożsamość napiętnowana. Socjologiczne stadium mechanizmów stygmatyzacji $i$ autostygmatyzacji na przykladzie kobiet z zespotem Turnera. Kraków: Nomos.

Toft, Daniel, J., and Kelly, M. Rehan. 2014. Estrogen replacement therapy for Turner syndrome hormones for healthy female sex development. Available from: https://www.endocrineweb.com/conditions/turner-syndrome/estrogen-replacement-therapyturner-syndrome [Accessed: $30^{\text {th }}$ January 2020].

Tomasello, Michael. 2001. The cultural origins of human cognition. Cambridge, MA: Harvard University Press.

Zadrożna, Ilona. 2013. Social functioning of women with Turner syndrome research results \& discussion, Interdyscyplinarne Konteksty Pedagogiki Specjalnej, 1, 121-137. https://doi.org/10.14746/ikps.2013.1.07 